\title{
Validation of the 8th AJCC Cancer Staging System for Pancreas Neuroendocrine Tumors Using Korean Nationwide Surgery Database
}

\section{Yunghun You, $\mathrm{MD}^{1, a}$ \\ Jin-Young Jang, $M D, P h D^{2}$ \\ Song Cheol Kim, MD, PhD ${ }^{3}$ \\ Yoo-Seok Yoon, MD, PhD ${ }^{4}$ \\ Joon Seong Park, MD, PhD 5 \\ Chol Kyoon Cho, MD, PhD ${ }^{6}$ \\ Sang-Jae Park, MD, $\mathrm{PhD}^{7}$ \\ Jae Do Yang, MD, $P h D^{8}$ \\ Woo Jung Lee, MD, $P h D^{9}$ \\ Tae Ho Hong, MD, PhD 10 \\ Keun Soo Ahn, MD, PhD'11 \\ Chi-Young Jeong, MD, $P h D^{12}$ \\ Hyeon Kook Lee, MD, PhD'13 \\ Seung Eun Lee, MD, $\mathrm{PhD}^{14}$ \\ Young Hoon Roh, MD, PhD ${ }^{15}$ \\ Hee Joon Kim, MD ${ }^{16}$ \\ Hongbeom Kim, MD2,17 \\ In Woong Han, MD, PhD ${ }^{18}$}

${ }^{*} A$ list of author's affiliations appears at the end of the paper.

\section{Purpose}

The 8th edition of the American Joint Committee on Cancer (ACC) staging system for pancreatic neuroendocrine tumor (PNET) included several significant changes. We aim to evaluate this staging system compared to the 7th edition AJCC staging system and European Neuroendocrine Tumors Society (ENETS) system.

\section{Materials and Methods}

We used Korean nationwide surgery database (2000-2014). Of 972 patients who had undergone surgery for PNET, excluding patients diagnosed with ENETS/World Health Organization 2010 grade 3 (G3), only 472 patients with accurate stage were included.

Results

Poor discrimination in overall survival rate (OSR) was noted between AJCC 8th stage III and IV $(p=0.180)$. The disease-free survival (DFS) curves of 8th AJCC classification were well separated between all stages. Compared with stage I, the hazard ratio of II, III, and IV was $3.808,13.928$, and 30.618, respectively $(p=0.007, p<0.001$, and $p<0.001)$. The curves of OSR and DFS of certain prognostic group in AJCC 7th and ENETS overlapped. In ENETS staging system, no significant difference in DFS between stage IIB versus IIIA ( $p=0.909)$ and IIIA versus IIIB ( $p=0.291)$. In multivariable analysis, lymphovascular invasion ( $p=0.002)$, perineural invasion $(p=0.003)$, and grade $(p<0.001)$ were identified as independent prognostic factors for DFS.

\section{Conclusion}

This is the first large-scale validation of the AJCC 8th edition staging system for PNET. The revised 8th system provides better discrimination compared to that of the 7th edition and ENETS TNM system. This supports the clinical use of the system.

\section{Key words}

Correspondence: In Woong Han, MD, PhD Department of Surgery, Samsung Medical Center, Sungkyunkwan University School of Medicine, 81 Irwon-ro, Gangnam-gu, Seoul 06351, Korea

Tel: 82-2-3410-0772

Fax: 82-2-3410-6980

E-mail: cardioman76@gmail.com

Received January 10, 2019

Accepted April 17, 2019

Published Online April 19, 2019

*Yunghun You and Jin-Young Jang contributed equally to this work.

aPresent address: Department of Surgery, Samsung Medical Center, Sungkyunkwan University School of Medicine, Seoul, Korea
Validation, Neoplasm staging, Pancreatic neuroendocrine tumor 


\section{Introduction}

Pancreatic neuroendocrine tumors (PNET) account for less than $2 \%$ of total pancreatic cancer [1] and about $10 \%$ of tumor arising from pancreas [2]. Rare incidence and indolent biologic behavior have made it difficult to understand disease entity and establish staging tools for this disease [3,4]. However, the development of imaging technology in recent decades has led to sharp increase in incidence and prevalence [5]. In fact, a proposal for a TNM classification to help stratify the prognosis was not made until 2006 by Rindi et al. [6]. This proposal was ultimately adopted by European Neuroendocrine Tumors Society (ENETS) and has been validated in the subsequent studies [7-12]. Meanwhile, the American Joint Committee on Cancer (AJCC) staging system for PNET was first isolated from exocrine pancreatic adenocarcinoma staging system in 2010 based on studies by Bilimoria et al. [13]. The same classification criteria as in exocrine pancreatic adenocarcinoma were applied to PNET in this study. After that, numerous studies have evaluated the suitability of the AJCC 7th classification [12,14-16]. Of these, two large cohort studies $[7,14]$ have shown that the proportion of patients in stage III of the AJCC 7th edition, which is classified as unresectable case, is relatively small. In particular, poor discrimination between stage II and III was reported by Rindi et al.'s investigation [7]. Furthermore, many studies have raised questions about whether it is appropriate to apply pancreatic adenocarcinoma staging to PNET with other biological characteristics $[7,11,14,17,18]$. These findings support the need for revision of the AJCC 7th system for PNET.

As a result, the newly revised AJCC 8th staging system introduces the classification criteria asserted by ENETS and shows several significant changes (Tables 1-3). At first, PNET staging system has come out separate system and applied to the only G1 (ENETS/World Health Organization [WHO] 2010 grade 1), G2 (ENETS / WHO 2010 grade 2), and well-differentiated G3 tumors (ENETS/WHO 2010 grade 3) [19]. The remaining poorly differentiated G3 (ENETS/WHO 2010 grade 3) neuroendocrine carcinoma follows staging of exocrine pancreatic cancer. Second, the size of the tumor has become an important criterion to distinguish the $\mathrm{T}$ category and invasion of soft tissue around the pancreas was excluded from staging criteria. Third, adjacent organs invasion has been categorized as T4 category, together with unresectable cases such as major vascular invasion. Fourth, M1 category has been subsided according to metastatic sites.

However, several studies have been published that question whether the ENETS system should be accepted as a new staging system $[7,10,11]$. In particular, stage IIIB (any T N1 $\mathrm{M} 0$ ) has a relatively better prognosis than IIIA (T4 N0 M0) in these studies. In fact, the AJCC 8th manual does not distin- guish between specific substages (IIA vs. IIB and IIIA vs. IIIB) unlike ENETS system. In addition, defining adjacent organ invasion and major vascular invasion as the same T4 has an unnatural aspect in that it may confuse the concept of "resectable" or "unresectable."

Given these, we aim to validate the AJCC 8th staging system in the present study. For this purpose, survival curves were compared according to AJCC 7th, AJCC 8th system, and ENETS system. In addition, multivariate analysis was performed to determine the effect of each system on prognosis.

\section{Materials and Methods}

\section{Patients and data collection}

Using Korean Tumor Registry System-Biliary Pancreas (KOTUS-BP) and Korean Pancreas Surgery Club (KPSC) database, 972 patients who underwent surgery for PNET during 2000-2014 were identified. Seventeen Korean cancer centers provided data on PNET. Data from following centers was prospectively collected from electronic medical records and retrospectively reviewed: Seoul National University College of Medicine $(n=302)$, Asan Medical Center $(n=228)$, Samsung Medical Center ( $\mathrm{n}=175)$, Seoul National University Bundang Hospital ( $\mathrm{n}=82)$, Yonsei University College of Medicine ( $n=65)$, Gangnam Severance Hospital ( $n=33)$, Chonnam National University Hwasun Hospital ( $\mathrm{n}=23)$, Seoul St. Mary's Hospital ( $n=17)$, Keimyung University Dongsan Medical Center ( $\mathrm{n}=12)$, National Cancer Center $(\mathrm{n}=9)$, Chung-Ang University Hospital ( $\mathrm{n}=5)$, Ewha Womans University Mokdong Hospital ( $\mathrm{n}=5)$, Gyeongsang National University Hospital ( $\mathrm{n}=5)$, Chonbuk National University Medical School $(\mathrm{n}=4)$, Chonnam National University Medical School $(\mathrm{n}=3)$, Dong-A University Hospital ( $\mathrm{n}=3)$, and Dongguk University Ilsan Hospital $(\mathrm{n}=1)$. Of these patients, $500(51.4 \%)$ were excluded, including 409 (42.1\%) with no acquired lymph nodes, $36(3.7 \%)$ with insufficient information to define T category and $\mathrm{M}$ category according to AJCC and ENETS classifications, $14(1.4 \%)$ whose tumor grade was not analyzed, one $(0.1 \%)$ without follow-up data and $40(4.1 \%)$ with G3 tumor grade. The remaining 472 patients (214 males and 258 females) with a median age of 54.7 years were enrolled in this study.

Variables collected for the database included age at diagnosis, gender, type of surgery, tumor size, location, adjacent organs invasion, margin status, lymphovascular invasion (LVI), perineural invasion (PNI), ENETS-WHO 2010 tumor grading [19], mitotic count, Ki67 index, and tumor stage by 
Table 1. The definition of AJCC 7th, 8th staging and the ENETS staging for pancreatic neuroendocrine tumor

\begin{tabular}{|c|c|c|}
\hline & AJCC 7th staging classification & AJCC 8th staging classification \\
\hline $\mathrm{T} 1$ & $\begin{array}{l}\text { Limited to the pancreas, } \\
\leq 2 \mathrm{~cm} \text { in greatest dimension }\end{array}$ & Tumor limited to the pancreas, $<2 \mathrm{~cm}$ \\
\hline $\mathrm{T} 2$ & $\begin{array}{l}\text { Limited to the pancreas, } \\
>2 \mathrm{~cm} \text { in greatest dimension }\end{array}$ & Tumor limited to the pancreas, $2-4 \mathrm{~cm}$ \\
\hline $\mathrm{T} 3$ & $\begin{array}{l}\text { Beyond the pancreas but without involvement } \\
\text { of the superior mesenteric artery }\end{array}$ & $\begin{array}{l}\text { Tumor limited to the pancreas, }>4 \mathrm{~cm} \text {, } \\
\text { or invading the duodenum or common bile duct }\end{array}$ \\
\hline $\mathrm{T} 4$ & $\begin{array}{l}\text { Involvement of the celiac axis or } \\
\text { uperior mesenteric artery (unresectable tumor) }\end{array}$ & Tumor invades adjacent structures ${ }^{\mathrm{a})}$ \\
\hline No & No regional lymph node metastasis & No regional lymph node metastasis \\
\hline N1 & Regional lymph node metastasis & Regional lymph node metastasis \\
\hline M0 & No distant metastasis & No distant metastasis \\
\hline M1 & Distant metastasis & Distant metastasis \\
\hline M1a & & Metastasis confined to liver \\
\hline M1b & & Metastasis in at least one extrahepatic site ${ }^{\mathrm{b})}$ \\
\hline M1c & & Both hepatic and extrahepatic metastases \\
\hline
\end{tabular}

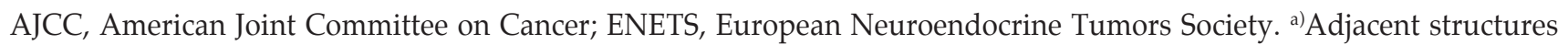
include stomach, spleen, colon, adrenal gland, or the wall of large vessels (celiac axis or the superior mesenteric artery),

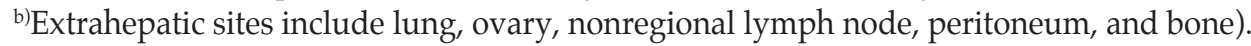

Table 2. Prognostic stage groups based on AJCC 7th, 8th staging and the ENETS staging

\begin{tabular}{|c|c|c|c|c|c|c|c|}
\hline \multicolumn{4}{|c|}{ AJCC 7th prognostic stage groups } & \multicolumn{4}{|c|}{ AJCC 8th and ENETS prognostic stage groups } \\
\hline Stage & $\mathbf{T}$ & $\overline{\mathbf{N}}$ & $\mathbf{M}$ & Stage & $\mathrm{T}$ & $\overline{\mathbf{N}}$ & $\mathbf{M}$ \\
\hline IA & T1 & N0 & M0 & I & T1 & N0 & M0 \\
\hline IB & $\mathrm{T} 2$ & N0 & M0 & II $(\mathrm{A})^{\mathrm{a})}$ & $\mathrm{T} 2$ & No & M0 \\
\hline IIA & $\mathrm{T} 3$ & N0 & M0 & II $(B)^{a)}$ & T3 & N0 & M0 \\
\hline IIB & T1-3 & N1 & M0 & III $(\mathrm{A})^{\mathrm{a})}$ & $\mathrm{T} 4$ & N0 & M0 \\
\hline III & $\mathrm{T} 4$ & Any N & M0 & III $(B)^{a)}$ & Any T & N1 & M0 \\
\hline IV & Any T & Any N & M1 & IV & Any T & Any N & M1 \\
\hline
\end{tabular}

AJCC, American Joint Committee on Cancer; ENETS, European Neuroendocrine Tumors Society. ${ }^{\text {a) }}$ Stage II (A/B) and III $(\mathrm{A} / \mathrm{B})$ are only used in ENETS system.

Table 3. Cross-tabulation presenting cancer staging distributions

\begin{tabular}{lcccc} 
& AJCC 8th I & AJCC 8th II & AJCC 8th III & AJCC 8th IV \\
AJCC 7th I & 167 & 141 & 0 & 0 \\
AJCC 7th II & 0 & 69 & 3 & 0 \\
AJCC 7th III & 0 & 0 & 0 & 0 \\
AJCC 7th IV & 0 & 0 & 0 & 19 \\
\hline
\end{tabular}

AJCC, American Joint Committee on Cancer. 
Table 4. Clinical and pathological features of PNET

\begin{tabular}{|c|c|}
\hline Variable & No. $(\%)(n=472)$ \\
\hline Age (yr) & $55.5(15.0-78.0)$ \\
\hline \multicolumn{2}{|l|}{ Sex } \\
\hline Male & $214(45.4)$ \\
\hline Female & $258(54.6)$ \\
\hline \multicolumn{2}{|l|}{ Operation } \\
\hline Pancreaticoduodenectomy & $210(44.4)$ \\
\hline Distal pancreatectomy & $179(37.9)$ \\
\hline Central pancreatectomy & $15(3.1)$ \\
\hline Enucleation & $44(9.3)$ \\
\hline Others ${ }^{a)}$ & $24(5.3)$ \\
\hline \multicolumn{2}{|l|}{ Type of operation } \\
\hline Open & 328 (69.5) \\
\hline Laparoscopic & $137(29.0)$ \\
\hline Robotic & $7(1.5)$ \\
\hline Tumor size (cm) & $3.0 \pm 2.1$ \\
\hline Tumor location & $469^{\mathrm{b})}$ \\
\hline Head only & $257(54.8)$ \\
\hline Body-tail only & $207(44.1)$ \\
\hline Head and body-tail or diffuse & $5(1.1)$ \\
\hline \multicolumn{2}{|l|}{ Resection margin status } \\
\hline R0 & $443(93.8)$ \\
\hline R1 & $10(2.1)$ \\
\hline R2 & $19(4.1)$ \\
\hline Lymphovascular invasion & $92(19.5)$ \\
\hline Perineural invasion & $83(17.6)$ \\
\hline \multicolumn{2}{|l|}{ Grade (ENETS/WHO 2010) } \\
\hline G1 & $319(67.6)$ \\
\hline G2 & $153(32.4)$ \\
\hline \multicolumn{2}{|l|}{ AJCC 7th T category } \\
\hline $\mathrm{T} 1$ & $177(37.5)$ \\
\hline $\mathrm{T} 2$ & $157(33.3)$ \\
\hline $\mathrm{T} 3$ & $134(28.4)$ \\
\hline $\mathrm{T} 4$ & $4(0.8)$ \\
\hline \multicolumn{2}{|l|}{ AJCC 8th T category } \\
\hline $\mathrm{T} 1$ & $177(37.5)$ \\
\hline $\mathrm{T} 2$ & $149(31.6)$ \\
\hline T3 & $130(27.5)$ \\
\hline $\mathrm{T} 4$ & $16(3.4)$ \\
\hline \multicolumn{2}{|l|}{ AJCC 7th \& 8th $\mathrm{N}$ category } \\
\hline No & $392(83.1)$ \\
\hline N1 & $80(16.9)$ \\
\hline \multicolumn{2}{|l|}{ AJCC 7th M category } \\
\hline M0 & $453(96.0)$ \\
\hline M1 & $19(4.0)$ \\
\hline AJCC 8th M category & $466^{\mathrm{b})}$ \\
\hline M0 & $453(97.3)$ \\
\hline M1a & $10(2.1)$ \\
\hline M1b & 0 \\
\hline M1c & $3(0.6)$ \\
\hline
\end{tabular}

(Continued)
Table 4. Continued

\begin{tabular}{lc} 
Variable & No. $(\%)(\mathbf{n}=472)$ \\
AJCC 7th prognostic stage group & \\
IA & $167(35.4)$ \\
IB & $141(29.9)$ \\
IIA & $73(15.5)$ \\
IIB & $69(14.6)$ \\
III & $3(0.6)$ \\
IV & $19(4.0)$ \\
AJCC 8th prognostic stage group & \\
I & $167(35.4)$ \\
II (A) ${ }^{c)}$ & $135(28.6)$ \\
II (B) & $75(15.9)$ \\
III $(A)^{c)}$ & $7(1.5)$ \\
III $(B)^{c)}$ & $69(14.6)$ \\
IV & $19(4.0)$ \\
\hline
\end{tabular}

PNET, pancreatic neuroendocrine tumor; ENETS, European Neuroendocrine Tumors Society; WHO, World Health Organization; AJCC, American Joint Committee on

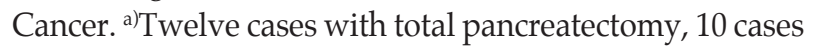
with open pancreatic biopsy and 2 cases of hepatopancreatoduodenectomy, ${ }^{\mathrm{b})}$ No. of valid PNETs, ${ }^{\mathrm{c}}$ Stage II (A/B) and III (A/B) are only used in ENET system.

7th AJCC classification [20]. In order to validation of 8th AJCC and ENETS classification, restaging was performed. To achieve this, data on tumor size and adjacent organs involved were used. Special attention has been given to the registration of pathologic reports analyzed in our database according to ENETS/WHO 2010 grading. If information on the tumor grade is missing, each center is requested to supplement and achieve it as much as possible. The overall survival time was defined as the time from the first diagnostic date to the date of death or last known follow-up. Recurrence-free survival time was measured from the date of initial diagnosis until recurrence.

\section{Statistical analysis}

Overall survival rate (OSR) and disease-free survival rate (DFS) analyses were conducted using Kaplan-Meier curves. In order to access staging classification, log-rank tests were used. To identify independent prognostic factors, Cox proportional hazards regression was performed in multivariable analysis. The p-value less than 0.05 indicate statistical significance. Statistical analyses were conducted using the PASW Statistics ver. 23.0 (IBM Corp., Armonk, NY). 


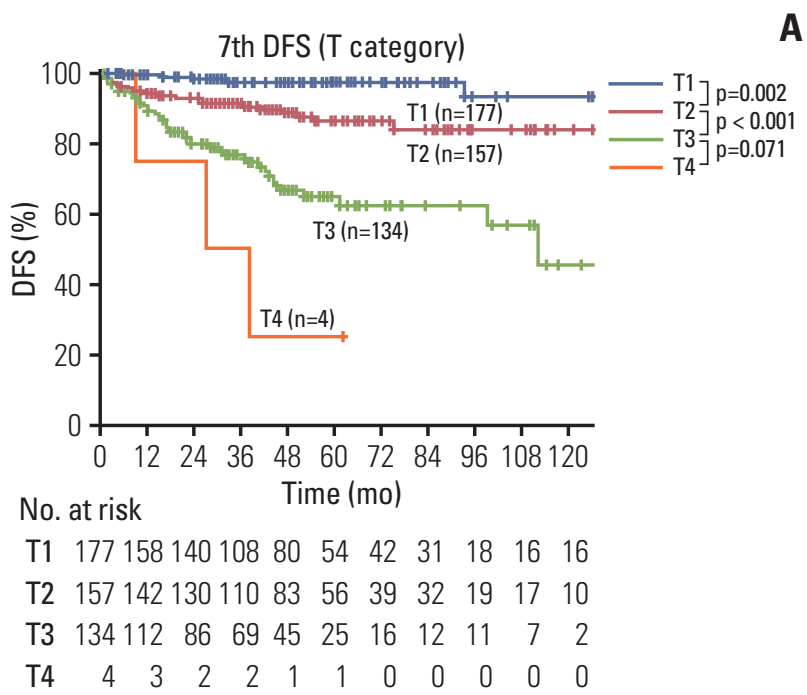

7th DFS (prognostic group)

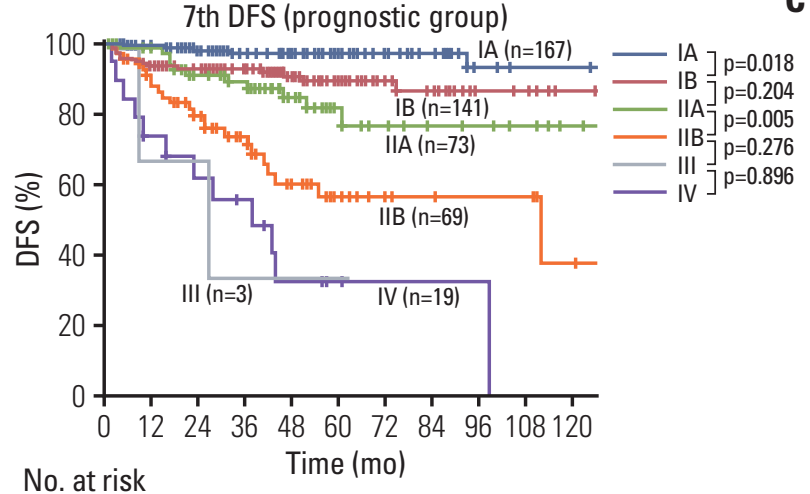

$\begin{array}{rrrrrrrrrrrr}\text { IA } & 167 & 151 & 132 & 104 & 77 & 54 & 42 & 31 & 18 & 16 & 16 \\ \text { IB } & 141 & 126 & 116 & 102 & 78 & 53 & 36 & 28 & 16 & 14 & 8 \\ \text { IIA } & 73 & 67 & 54 & 46 & 32 & 16 & 12 & 9 & 8 & 5 & 2 \\ \text { IIB } & 69 & 56 & 44 & 30 & 20 & 12 & 8 & 6 & 5 & 5 & 2 \\ \text { III } & 3 & 2 & 2 & 1 & 1 & 1 & 0 & 0 & 0 & 0 & 0 \\ \text { IV } & 19 & 13 & 10 & 8 & 4 & 2 & 1 & 1 & 1 & 0 & 0\end{array}$

C
A

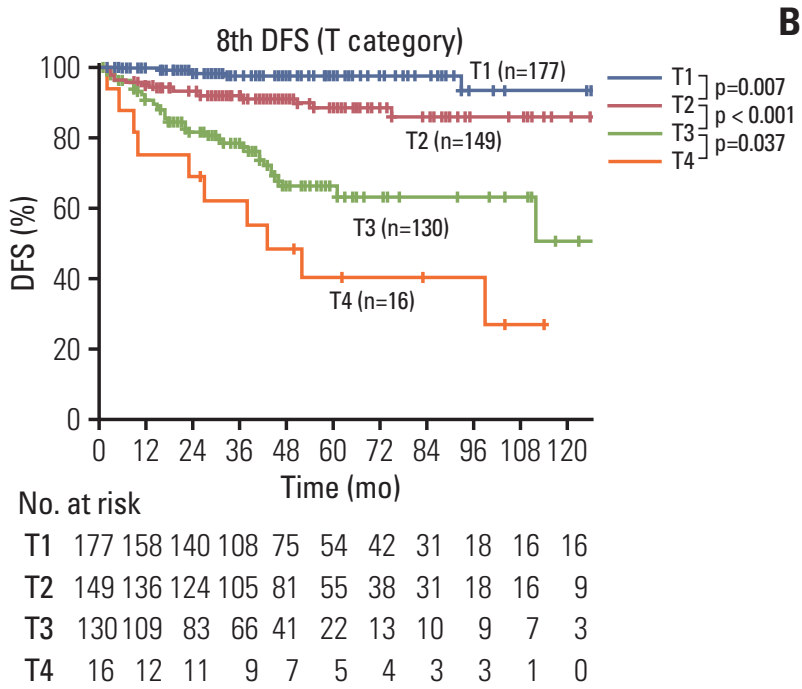

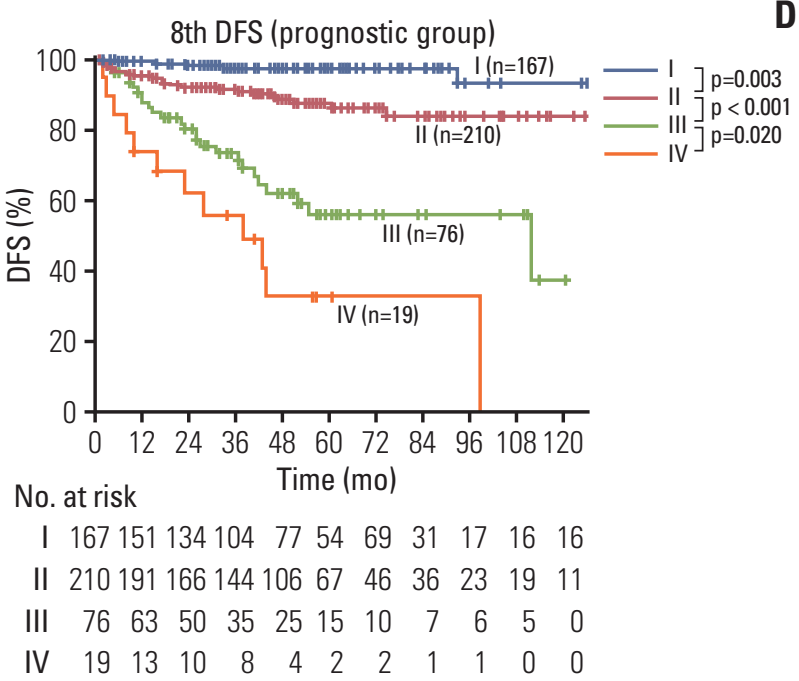

Fig. 1. Kaplan-Meier survival analysis of disease-free survival (DFS) according to $\mathrm{T}$ category of American Joint Committee on Cancer (AJCC) 7th edition (A), T category of AJCC 8th edition (B), 7th AJCC prognostic group (C), 8th AJCC prognostic group (D), European Neuroendocrine Tumors Society (ENETS) prognostic group (E), N category (F), 7th M category (G), 8th M category (H), and Grade (ENETS/ World Health Organization [WHO] 2010) (I). (Continued to the next page)

\section{Ethical statement}

This study was approved by Institutional Review Board of Samsung Medical Center, Seoul, Republic of Korea (approval number: 2017-12-107). Because the study was based on retrospective analysis using existing medical records, informed consent was not required.

\section{Results}

\section{Patient characteristics}

Patient characteristics of the 472 patients are summarized in Table 4. Pancreaticoduodenctomy and distal pancreatectomy were performed in $210(44.4 \%)$ and $179(37.9 \%)$, respectively. Minimally invasive surgery, including laparoscopic and robotic surgery was conducted in 144 (30.5\%). More than 

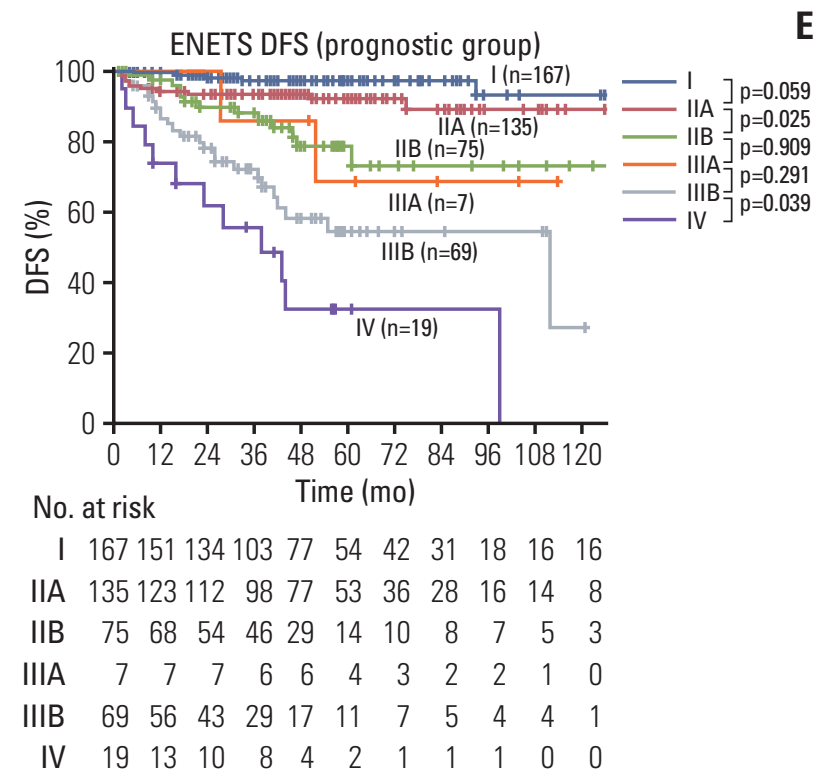

E

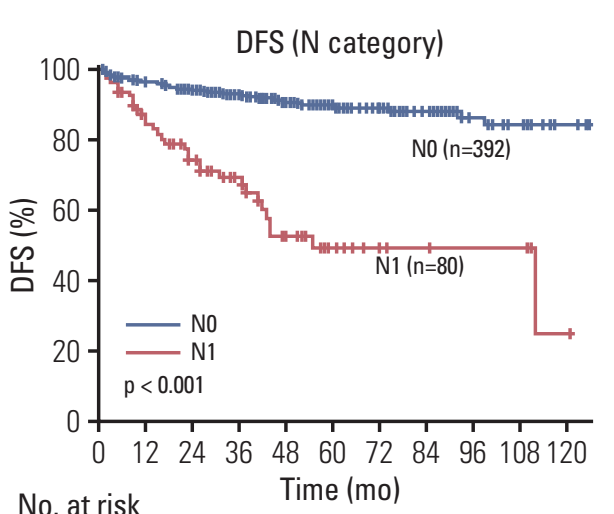

No. at risk

No $39235531225819212792 \quad 70 \quad 44 \quad 36 \quad 27$

$\begin{array}{llllllllllll}\mathrm{N} 1 & 80 & 62 & 48 & 33 & 19 & 11 & 6 & 5 & 4 & 4 & 1\end{array}$

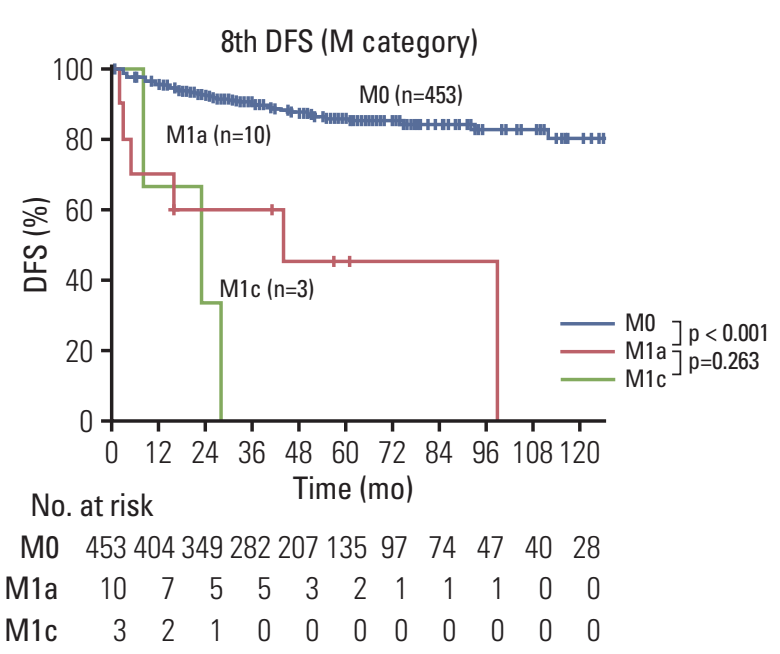

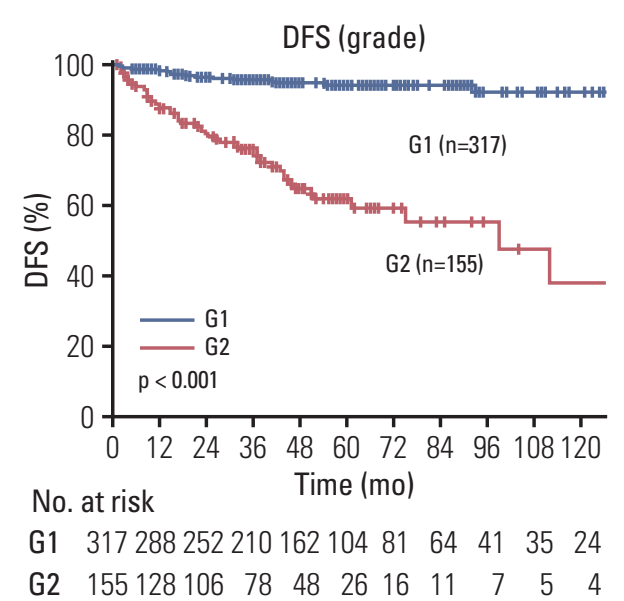

Fig. 1. (Continued from the previous page)

G1 $317288252210162104 \quad 81 \quad 64 \quad 41 \quad 35 \quad 24$ G2 $155128106 \quad 78 \quad 48 \quad 26 \quad 16 \quad 11 \quad 7 \quad 5 \quad 4$
No. at risk

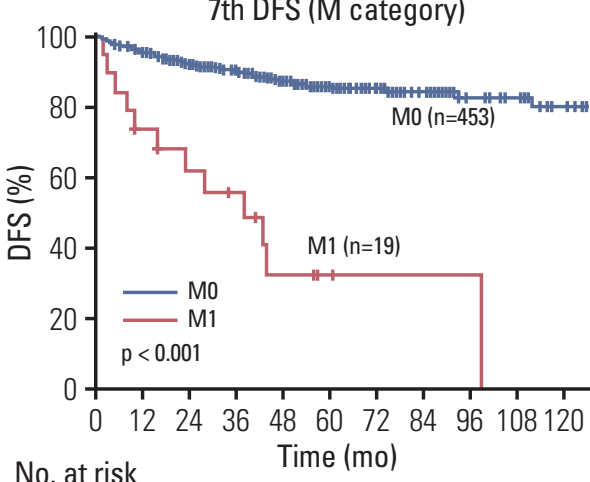

M0 $453405350283208136 \quad 98 \quad 75 \quad 48 \quad 41 \quad 28$ $\begin{array}{llllllllllll}\text { M1 } & 19 & 13 & 10 & 8 & 4 & 2 & 1 & 1 & 1 & 0 & 0\end{array}$
G

I 

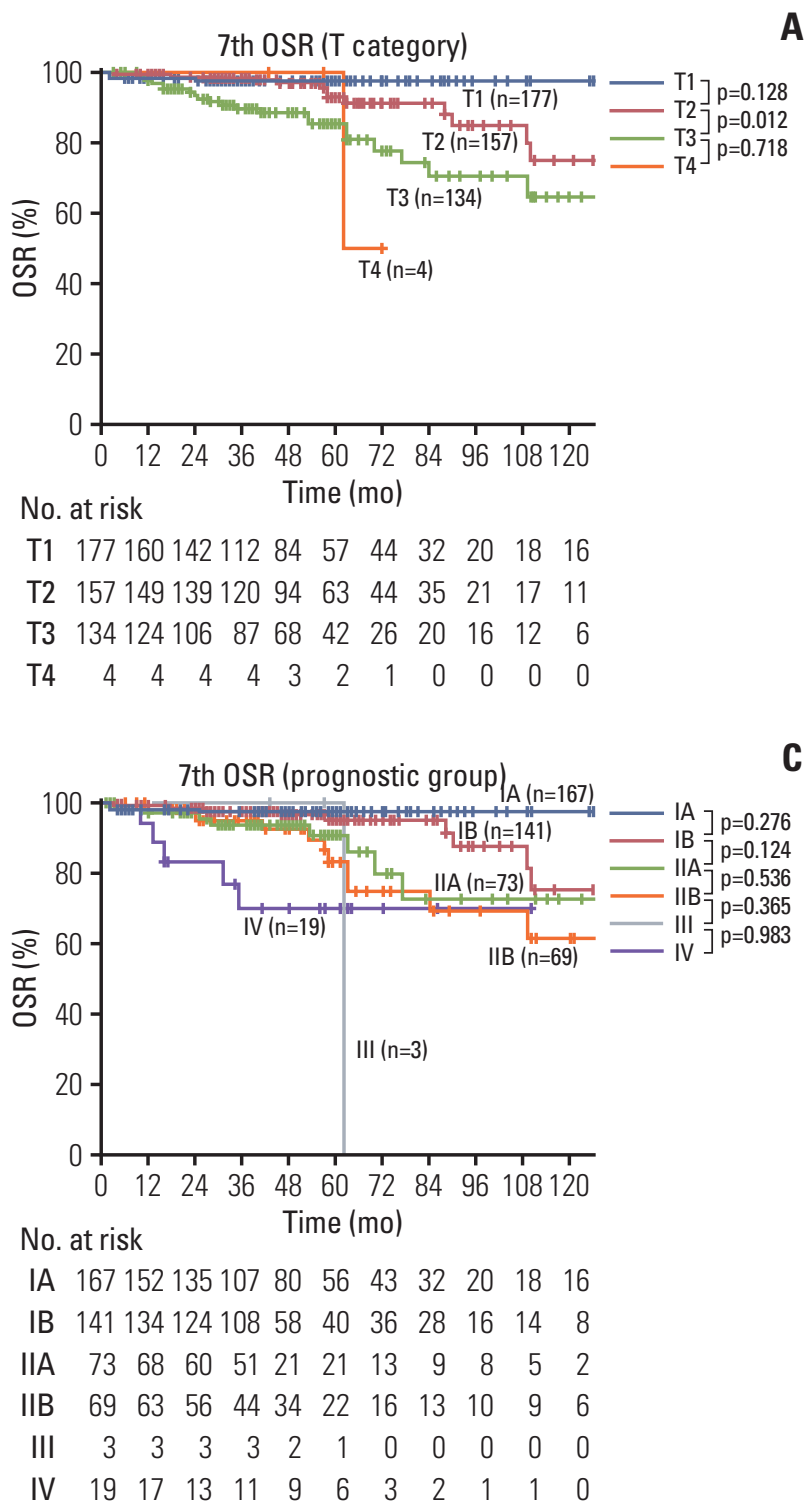

C
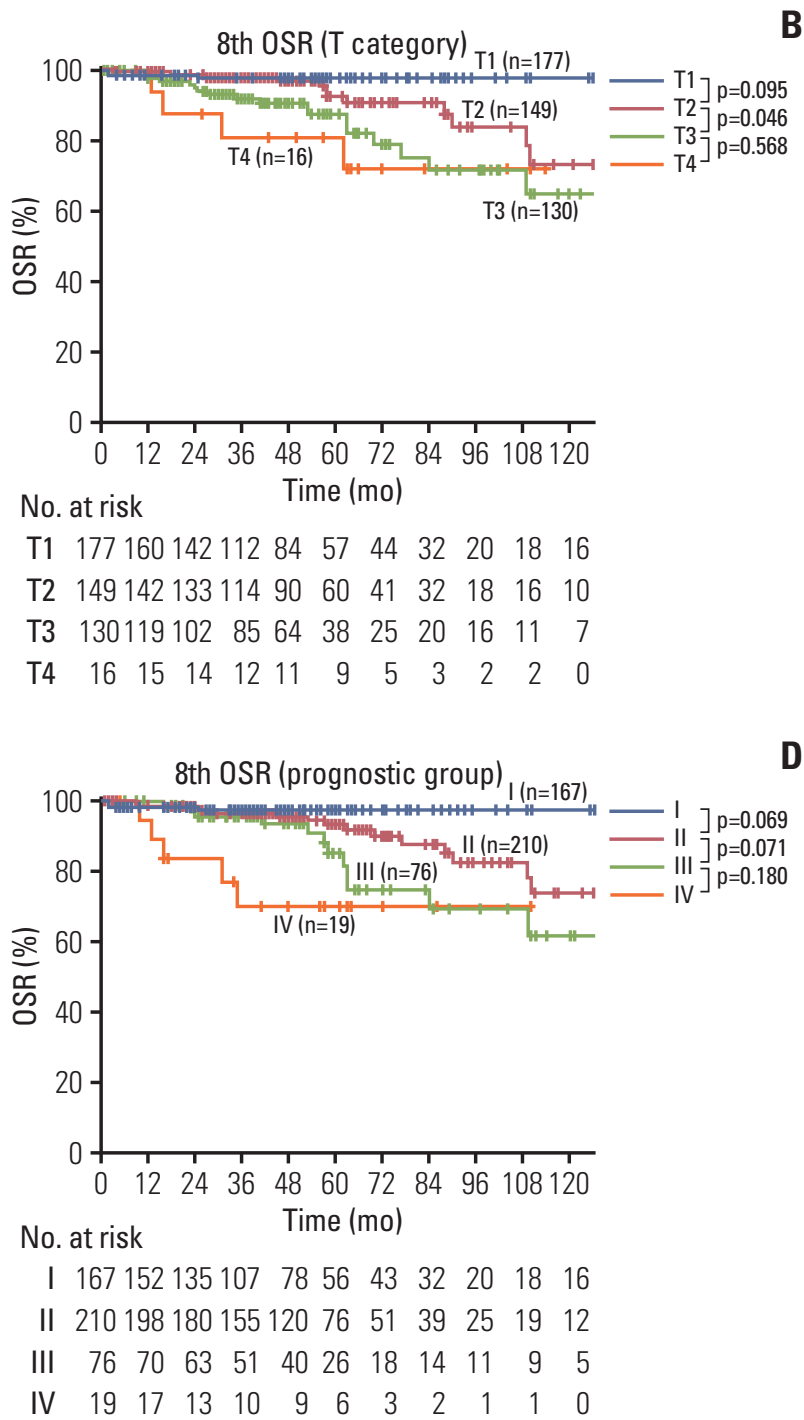

Fig. 2. Kaplan-Meier survival analysis of overall survival rate (OSR) according to $\mathrm{T}$ category of American Joint Committee on Cancer (AJCC) 7th edition (A), T category of AJCC 8th edition (B), 7th AJCC prognostic group (C), 8th AJCC prognostic group (D), European Neuroendocrine Tumors Society (ENETS) prognostic group (E), N category (F), 7th M category (G), 8th M category (H), and grade (ENETS / World Health Organization [WHO] 2010) (I). (Continued to the next page)

half of the patients had tumors located in the pancreatic head. The mean value of tumor size was $3.0 \pm 2.1 \mathrm{~cm}$. Curative resection was achieved in $443(93.8 \%)$. The proportion of LVI and PNI were $19.5 \%$ and $17.6 \%$, respectively. The number of patients with G1 ( $\mathrm{n}=319)$ nearly doubled compared to G2 $(n=153)$. The median or mean number of lymph nodes dissected were 2 (0-65) and 5.1 \pm 8.4 , respectively. Lymph node involvement was developed in $80(16.9 \%)$. According to the 7th AJCC staging classification, only $4(0.8 \%)$ was T4 category and $3(0.6 \%)$ had prognostic stage group III. In 8th AJCC edition, the number of patients with $\mathrm{T} 4$ and prognostic stage group of III increased to $16(3.4 \%)$ and $76(16.1 \%)$, respectively. Among 472, the median time of follow-up was 54 months (25th to 75th percentiles, 39-147). The cumulative OSR at 5 years and 10 years was $92.4 \%$ and $79.4 \%$, respectively. The cumulative DFS was $83.5 \%$ at 5 years and $76.4 \%$ at 10 years. 

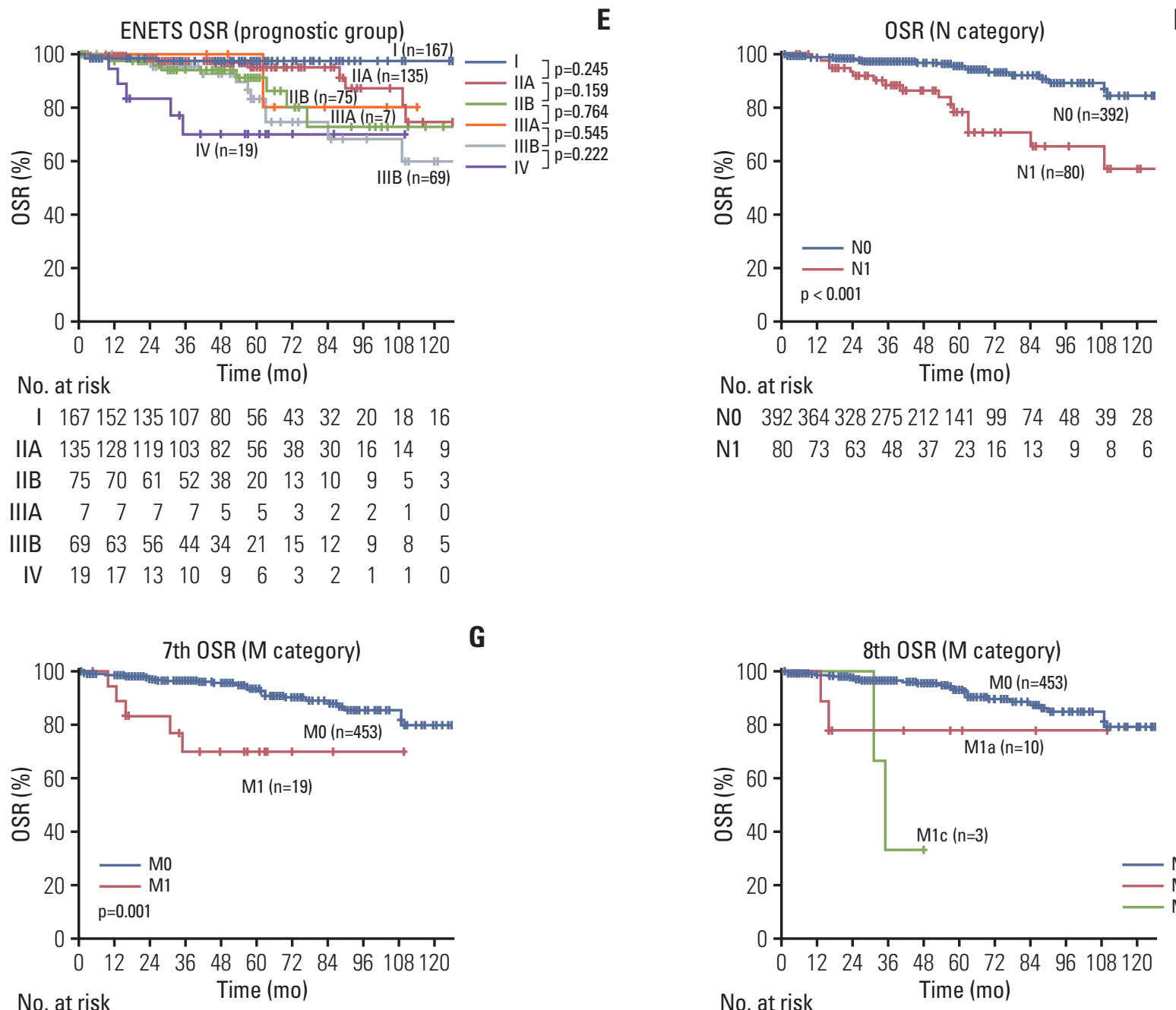

G
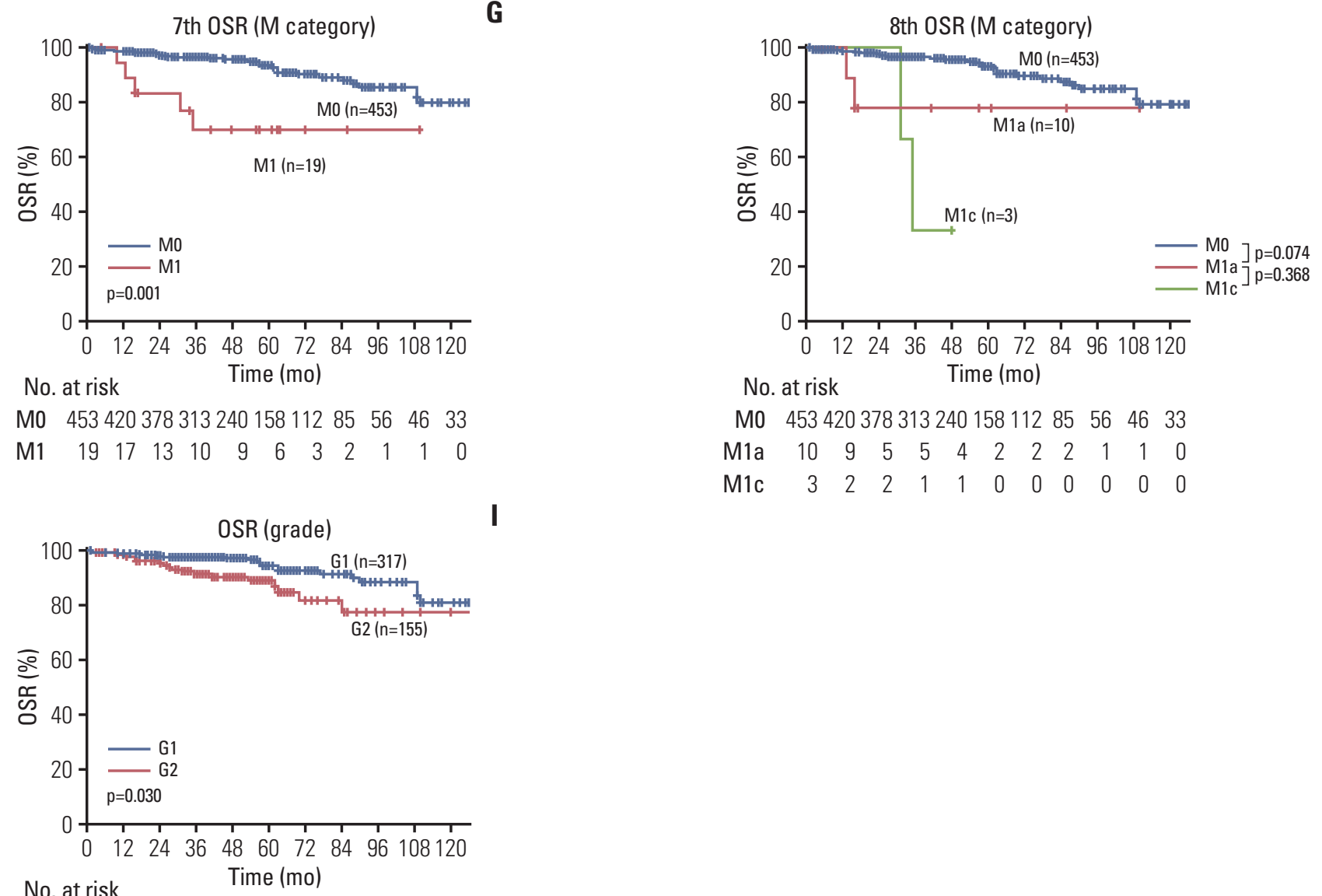

G1 $317292261222173117 \quad 87 \quad 68 \quad 45 \quad 37 \quad 25$

G2 $155145130101 \quad 76 \quad 47 \quad 28 \quad 19 \quad 12 \quad 10 \quad 8$

Fig. 2. (Continued from the previous page) 
Table 5. Univariable and multivariable analysis of prognostic factor for disease-free survival

\begin{tabular}{|c|c|c|c|c|c|c|c|c|c|}
\hline & \multicolumn{3}{|c|}{ Univariable analysis } & \multicolumn{3}{|c|}{$\begin{array}{c}\text { AJCC 7th } \\
\text { multivariable analysis }\end{array}$} & \multicolumn{3}{|c|}{$\begin{array}{c}\text { AJCC 8th } \\
\text { multivariable analysis }\end{array}$} \\
\hline & HR & \multicolumn{2}{|c|}{ p-value } & HR & $95 \% \mathrm{CI}$ & p-value & HR & $95 \% \mathrm{CI}$ & p-value \\
\hline \multicolumn{10}{|l|}{ Sex } \\
\hline Male & 1 & & & 1 & & & 1 & & \\
\hline Female & 0.541 & 0.020 & & 0.850 & $0.474-1.522$ & 0.584 & 0.854 & $0.478-1.524$ & 0.592 \\
\hline \multicolumn{10}{|c|}{ Resection margin status } \\
\hline R0 & 1 & & & 1 & & & 1 & & \\
\hline $\mathrm{R} 1 / \mathrm{R} 2$ & 4.223 & 0.001 & & 1.299 & $0.444-3.798$ & 0.633 & 1.223 & $0.421-3.551$ & 0.712 \\
\hline \multicolumn{10}{|c|}{ Lymphovascular invasion } \\
\hline No & 1 & & & 1 & & & 1 & & \\
\hline Yes & 6.951 & $<0.001$ & & 2.885 & $1.494-5.571$ & 0.002 & 2.885 & $1.494-5.571$ & 0.002 \\
\hline \multicolumn{10}{|c|}{ Perineural invasion } \\
\hline No & 1 & & & 1 & & & 1 & & \\
\hline Yes & 5.940 & 0.004 & & 2.474 & $1.352-4.527$ & 0.003 & 2.474 & $1.352-4.527$ & 0.003 \\
\hline \multicolumn{10}{|c|}{ Grade (ENETS/WHO 2010) } \\
\hline G1 & 1 & & & 1 & & & 1 & & \\
\hline G2 & 8.403 & $<0.001$ & & 5.026 & $2.516-10.043$ & $<0.001$ & 5.026 & $2.516-10.043$ & $<0.001$ \\
\hline AJCC 7th stage & & $<0.001$ & & & & 0.965 & & & \\
\hline I & 1 & & & 1 & & & & & \\
\hline II & 4.616 & $<0.001^{\mathrm{a})}$ & $0.312^{\mathrm{b})}$ & 0.855 & $0.376-1.944$ & 0.709 & & & \\
\hline III & 8.539 & $0.004^{\mathrm{a})}$ & $0.354^{\mathrm{b})}$ & 1.058 & $0.202-5.538$ & 0.947 & & & \\
\hline IV & 13.872 & $<0.001^{\mathrm{a})}$ & $0.521^{\mathrm{b})}$ & 0.761 & $0.200-2.898$ & 0.688 & & & \\
\hline AJCC 8th stage & & $<0.001$ & & & & & & & 0.633 \\
\hline I & 1 & & & & & & 1 & & \\
\hline II & 3.808 & $0.007^{\mathrm{a})}$ & $0.006^{\mathrm{b})}$ & & & & 1.717 & $0.628-4.693$ & 0.292 \\
\hline III & 13.928 & $<0.001^{\mathrm{a})}$ & $<0.001^{\mathrm{b})}$ & & & & 2.058 & $0.680-6.227$ & 0.201 \\
\hline IV & 30.618 & $<0.001^{\mathrm{a})}$ & $0.024^{\mathrm{b})}$ & & & & 2.158 & $0.541-8.613$ & 0.276 \\
\hline
\end{tabular}

AJCC, American Joint Committee on Cancer; HR, hazard ratio; CI, confidence interval; ENETS, European Neuroendocrine Tumors Society; WHO, World Health Organization. ${ }^{a)} \mathrm{p}$-values with stage I as the reference, ${ }^{b}$ p-values with the previous stage as the reference.

\section{DFS according to each staging system and tumor grade}

As shown in Fig. 1A, there is no significant difference in DFS between AJCC 7th T3 versus T4 ( $p=0.071)$. By contrast, regarding AJCC 8th T category, significant difference was shown between all T categories (Fig. 1B). Regarding prognostic stage groups, some of the DFS curves of 7th AJCC classification overlapped (IB vs. IIA, $\mathrm{p}=0.204$; IIB vs. III, $\mathrm{p}=0.276$; and III vs. IV, $\mathrm{p}=0.896$ ) (Fig. 1C). By contrast, DFS curves of 8th AJCC classification were well separated between all stages (Fig. 1D). Compared with stage I, the hazard ratio (HR) of II, III, and IV was 3.808, 13.928 and 30.618, respectively $(p=0.007, p<0.001$, and $p<0.001)$. In ENETS staging system, there was no significant difference in DFS between stage IIB versus IIIA ( $p=0.909)$ and IIIA versus IIIB ( $p=0.291)$, respectively (Fig. 1D). Significant difference in DFS according to $\mathrm{N}$ category, AJCC 7th M category, and grade was obser- ved $(\mathrm{p}<0.001, \mathrm{p}<0.001$, and $\mathrm{p}<0.001)$ (Fig. 1F, G, and I). No significant difference between AJCC 8th M1a versus M1c was found in DFS curves $(p=0.268)$ (Fig. $1 \mathrm{H})$.

\section{OSR according to each staging system and tumor grade}

Fig. 2A shows that OSR curves according to 7th AJCC T category are not well separated. In 8th AJCC edition, there was no significant difference in OSR curves between T3 and T4 ( $p=0.568$ ) (Fig. 2B). As shown in Fig. 2C and E, all OSR curves of AJCC 7th prognostic groups and ENETS overlapped. The 5-year and 10-year cumulative OSR according to AJCC 8th prognostic stage groups were as follows (Fig. 2D): IA (97.4\% and $97.4 \%)$, IB (95.1\% and $75.2 \%)$, IIA $(90.0 \%$ and $72.7 \%)$, IIB (83.2\% and $61.5 \%)$, III (100\% and $0 \%)$, and IV $(69.9 \%$ and $69.9 \%)$. Poor discrimination of curves was shown between III versus IV ( $\mathrm{p}=0.180)$. Fig. IF, 2F, and G rep- 
Table 6. Univariable and multivariable analysis of prognostic risk factor for overall survival rate

\begin{tabular}{|c|c|c|c|c|c|c|c|c|c|}
\hline & \multicolumn{3}{|c|}{ Univariable analysis } & \multicolumn{3}{|c|}{$\begin{array}{c}\text { AJCC 7th } \\
\text { multivariable analysis }\end{array}$} & \multicolumn{3}{|c|}{$\begin{array}{c}\text { AJCC 8th } \\
\text { multivariable analysis }\end{array}$} \\
\hline & HR & \multicolumn{2}{|c|}{ p-value } & HR & $95 \% \mathrm{CI}$ & p-value & HR & $95 \% \mathrm{CI}$ & $\overline{p \text {-value }}$ \\
\hline Age (continuous) & 1.033 & \multicolumn{2}{|c|}{0.078} & 4.053 & $1.826-8.998$ & 0.001 & 1.069 & $1.028-1.111$ & 0.001 \\
\hline \multicolumn{10}{|c|}{ Resection margin status } \\
\hline R0 & 1 & \multirow{2}{*}{\multicolumn{2}{|c|}{0.004}} & 1 & & & 1 & & \\
\hline R1/R2 & 4.246 & & & 2.228 & $0.457-10.875$ & 0.322 & 1.855 & $0.404-8.517$ & 0.427 \\
\hline \multicolumn{10}{|c|}{ Lymphovascular invasion } \\
\hline No & 1 & & & 1 & & & 1 & & \\
\hline Yes & 3.058 & \multicolumn{2}{|l|}{0.007} & 2.235 & $0.842-5.934$ & 0.106 & 2.795 & $1.128-6.925$ & 0.026 \\
\hline \multicolumn{10}{|c|}{ Perineural invasion } \\
\hline No & 1 & & & 1 & & & 1 & & \\
\hline Yes & 3.757 & \multicolumn{2}{|l|}{0.008} & 1.549 & $0.555-4.329$ & 0.404 & 1.779 & $0.696-4.549$ & 0.229 \\
\hline \multicolumn{10}{|c|}{ Grade (ENETS/WHO 2010) } \\
\hline G1 & 1 & & & 1 & & & 1 & & \\
\hline G2 & 2.478 & \multicolumn{2}{|l|}{0.021} & 1.250 & $0.486-3.127$ & 0.644 & 1.559 & $0.631-3.852$ & 0.336 \\
\hline AJCC 7th stage & & \multicolumn{2}{|l|}{0.001} & & & 0.387 & & & \\
\hline I & 1 & & & 1 & & & & & \\
\hline II & 2.734 & $0.002^{\mathrm{a})}$ & $0.001^{\mathrm{b})}$ & 2.440 & $0.848-7.016$ & 0.098 & & & \\
\hline III & 3.445 & $0.230^{\mathrm{a})}$ & $0.792^{b)}$ & 1.362 & $0.135-13.713$ & 0.793 & & & \\
\hline IV & 5.922 & $<0.001^{\mathrm{a})}$ & $0.763^{b)}$ & 1.757 & $0.234-13.176$ & 0.584 & & & \\
\hline AJCC 8th stage & & 0.001 & & & & & & & 0.098 \\
\hline I & 1 & & & & & & 1 & & \\
\hline II & 2.268 & $0.085^{a)}$ & $0.077^{\mathrm{b})}$ & & & & 4.357 & $0.981-19.355$ & 0.053 \\
\hline III & 4.459 & $0.003^{\mathrm{a})}$ & $0.077^{\mathrm{b})}$ & & & & 5.310 & $1.001-28.154$ & 0.050 \\
\hline IV & 9.802 & $<0.001^{\mathrm{a})}$ & $0.190^{\mathrm{b})}$ & & & & 6.509 & $0.808-52.472$ & 0.079 \\
\hline
\end{tabular}

AJCC, American Joint Committee on Cancer; HR, hazard ratio; CI, confidence interval; ENETS, European Neuroendocrine Tumors Society; WHO, World Health Organization. ${ }^{a} \mathrm{p}$-values with stage I as the reference, ${ }^{b} \mathrm{p}$-values with the previous stage as the reference.

resented that significant difference in OSR according to $\mathrm{N}$ category, AJCC 7th M category and grade $(\mathrm{p}<0.001, \mathrm{p}=0.001$, and $\mathrm{p}=0.030$ ). Regarding 8 th M category, OSR curves of all stages overlapped (Fig. 2H).

\section{Prognostic factor analyses (risk factor for DFS)}

In a univariable analysis of risk factor for DFS, sex (HR, $0.541 ; 95 \%$ confidence interval [CI], 0.320 to $0.913 ; \mathrm{p}=0.020$ ), resection margin status (HR, 4.223; 95\% CI, 1.896 to 9.406; $\mathrm{p}=0.001)$, LVI (HR, 6.951; 95\% CI, 3.862 to 12.509; $\mathrm{p}<0.001$ ), PNI (HR, 5.940; 95\% CI, 3.215 to 10.976; $\mathrm{p}=0.004)$, grade (HR, 8.403; 95\% CI, 4.642 to 15.212; $\mathrm{p}<0.001)$, AJCC 7th staging groups (compared with stage I: HR of II, 4.616; 95\% CI, 2.629 to 8.103 ; $\mathrm{p}<0.001$; HR of III, $8.539 ; 95 \%$ CI, 1.984 to 36.745 ; $\mathrm{p}=0.004$; and HR of IV, 13.872; 95\% CI, 6.704 to 28.701; $\mathrm{p}<$ 0.001), and AJCC 8th staging groups (compared with stage I: HR of II, 3.808; 95\% CI, 1.453 to 9.998; $\mathrm{p}=0.007$; HR of III, 13.928; 95\% CI, 5.341 to 36.319; $\mathrm{p}<0.001$; and HR of IV, 30.618;
95\% CI, 10.749 to $87.219 ; \mathrm{p}<0.001$ ) were revealed as significant factors. In a multivariable analysis, LVI (HR, 2.885; 95\% CI, 1.494 to 5.571; $\mathrm{p}=0.002)$, PNI (HR, 2.474; $95 \% \mathrm{CI}, 1.352$ to 4.527; $\mathrm{p}=0.003$ ), and grade (HR, 5.026; 95\% CI, 2.516 to 10.043 ; $\mathrm{p}<0.001$ ) were identified as independent prognostic factors for DFS. The remaining factors such as sex (HR, 0.854; 95\% $\mathrm{CI}, 0.478$ to $1.524 ; \mathrm{p}=0.592$ ), resection margins status (HR, $1.223 ; 95 \% \mathrm{CI}, 0.421$ to $3.551 ; \mathrm{p}=0.712)$, AJCC 7 th staging groups (compared with stage I: HR of II, $0.855 ; 95 \%$ CI, 0.376 to $1.944 ; p=0.709$; HR of III, $1.058 ; 95 \% \mathrm{CI}, 0.202$ to 5.538 ; $p=0.947$; and HR of IV, $0.761 ; 95 \%$ CI, 0.200 to $2.898 ; p=0.688$ ), and AJCC 8th staging groups (compared with stage I: HR of II, $1.717 ; 95 \%$ CI, 0.628 to $4.693 ; p=0.292$; HR of III, 2.058; $95 \%$ CI, 0.680 to $6.227 ; \mathrm{p}=0.201$; and HR of IV, $2.158 ; 95 \%$ CI, 0.541 to $8.613 ; \mathrm{p}=0.276$ ) were not significant in multivariable analysis. These results were summarized in Table 5. 


\section{Analysis of risk factor for OSR}

In a univariable analysis of risk factor for OSR, age (HR, $1.033 ; 95 \% \mathrm{CI}, 0.996$ to $1.070 ; \mathrm{p}=0.078)$, resection margin status (HR, 4.246; 95\% CI, 1.599 to $11.276 ; \mathrm{p}=0.004)$, LVI (HR, 3.058 ; 95\% CI, 1.349 to $6.931 ; \mathrm{p}=0.007)$, PNI (HR, 3.757; 95\% $\mathrm{CI}, 1.410$ to $10.011 ; \mathrm{p}=0.008)$, grade (HR, 2.478; 95\% CI, 1.146 to $5.360 ; \mathrm{p}=0.021$ ), AJCC 7th staging groups (compared with stage I: HR of II, 2.734; 95\% CI, 1.444 to $5.174 ; \mathrm{p}=0.002 ; \mathrm{HR}$ of III, 3.445; 95\% CI, 0.458 to 25.920; $\mathrm{p}=0.230$; and HR of IV, 5.922; 95\% CI, 2.182 to 16.069; $\mathrm{p}<0.001$ ), and AJCC 8th staging groups (compared with stage I: HR of II, 2.268; 95\% CI, 0.893 to 5.758 ; $\mathrm{p}=0.085$; HR of III, $4.459 ; 95 \% \mathrm{CI}, 1.672$ to 11.892; $\mathrm{p}=0.003$; and HR of IV, 9.802; 95\% CI, 2.967 to 32.386; $\mathrm{p}<0.001)$ were significant factors. In a multivariable analysis, age was identified as independent risk factor for OSR (HR, 1.609; 95\% CI, 1.028 to 1.111; $\mathrm{p}=0.001$ ) and AJCC 8th staging groups was marginally significant (compared with stage I: HR of II, 4.357; 95\% CI, 0.981 to 19.355; $\mathrm{p}=0.053$; HR of III, 5.310; 95\% CI, 1.001 to 28.154; $\mathrm{p}=0.050$; and HR of IV, 6.509; $95 \%$ CI, 0.808 to 52.472; $\mathrm{p}=0.079$ ). However, AJCC 7th staging groups was not significant (compared with stage I: HR of II, 2.440; 95\% CI, 0.848 to 7.016; $\mathrm{p}=0.098$; HR of III, $1.362 ; 95 \%$ $\mathrm{CI}, 0.135$ to 13.713 ; $\mathrm{p}=0.793$; and HR of IV, 1.757; 95\% CI, 0.234 to $13.176 ; \mathrm{p}=0.584$ ) in multivariable analysis. Table 6 summarized these results.

\section{Discussion}

To best of our knowledge, this is the first study to validate a new AJCC 8th staging classifications for PNET. In fact, validation of the ENETs system, which is the basis for 8th AJCC staging system, has been carried out in several studies [712,21]. Unlike previous studies, the strength of the present study is that it allows accurate assessment of lymph node metastasis. Recent studies have supported lymph node metastasis as a predictor of poor prognosis $[22,23]$. If accurate assessment of the $\mathrm{N}$ category through lymph node sampling or lymphadenectomy is not feasible, accurate TNM staging to predict prognosis becomes difficult. The low lymph node yield rate, including zero percent, is likely to be related to the type of surgery and the individual preference of the operator for PNET. In a single-center study, the rate of no lymph node sampling is higher in patients undergoing enucleation and spleen-preserving distal pancreatectomy compared to patients with other operations [24]. In this regards, previous studies to validate ENETS TNM staging had limitation. In a European multicenter study by Rindi et al. [7] using 1,072 cohorts, the lymph node status could not be assessed in 737
$(68.8 \%)$ patients. The results of a study conducted by Luo et al. [21] using 2,529 cases from Surveillance, Epidemiology, and End Results data should also be cautious about the proper evaluation of staging system because there is no mention of " $\mathrm{Nx}$ ". Besides, in the previous two studies mentioning " $\mathrm{Nx}$ ", the ratio of " $\mathrm{Nx}$ " in all patients was reported as $51.6 \%$ and $68.8 \%$, respectively $[8,9]$. In the current study, among the 972 patients who underwent resection with PNET, 409 patients $(42.1 \%)$ had no lymph node retrieval and contrary to previous studies mentioned above, we excluded samples from the survival analysis that were not correctly evaluated for lymph node status. The inclusion criteria of the current study, which reflects our intent to not ignore the prognostic significance of lymph node status, seems to provide more accurate validation of the AJCC 8th TNM staging system.

An important change in 8th edition of AJCC system is that G3 was not included in the PNET staging system unlike the previous ENETS system. This reflects the results of previous studies showing that exocrine tumors and neuroendocrine tumors have different tumor biology and prognosis [7,11,14, $17,18,25]$. In the former ENETS validation study, the proportion of G3 ranging from $6.8 \%$ to $11.0 \%$ was not negligible $[7-12,21]$. By contrary, we used the cohort excluding G3 in this study. This may have helped to evaluate more elaborately the suitability of the new AJCC staging system for PNET.

The present study largely supports that AJCC 8th edition staging system provides better discrimination when compared to the AJCC 7th edition and the ENETS staging system. As for DFS, survival curves of 8th AJCC classification were well separated between all stages. This seems to be related to some detailed changes in the 8th edition as follows. First, the definition of T4 category expanded to adjacent organ invasion, which affected the increase of T4 case number (Figs. 1A, B, 2A, and B). As a result, four T4 patients increased to 16 followed by the increases in stage III cases. Second, T1-3N1M0 (which had been stage IIB in AJCC 7th system) is classified as stage III in the AJCC 8th staging system, leading to an increase in the proportion of stage III. The two changes described above resulted in an increase in the ratio of stage III in the 8th AJCC and a significant difference in DFS curves between stages (stage II vs. III and stage III vs. IV in 8th AJCC staging system).

Another remarkable result of this study is that it is more reasonable to combine stage IIIA (T4, N0, M0) and IIIB (any $\mathrm{T}, \mathrm{N} 1, \mathrm{M} 0$ ) into one prognostic group than to divide stage III into two subgroups. In fact, the results that stage IIIB has a better prognosis than IIIA has already been reported in previous studies [7,10,11]. Rindi et al. [7] estimated this to be due to poorer prognosis of the unresectable T4 compared with positive $\mathrm{N}$ cases, or different surgical techniques and lymph node sampling methods, or small sample size of T4. In the 
current study, there was also no significant difference in survival rate (both OSR and DFS) between the stage IIIA and IIIB using the ENETS system ( $\mathrm{p}=0.291$ and $\mathrm{p}=0.545$ ), respectively (Figs. 1D and 2D). Given these, the attempt at the AJCC 8th edition, which classifies the existing ENETS stage into four simple stages, is considered acceptable.

Despite a better distribution of prognosis in different stages based on the new AJCC revision, the low stage IV (Any T Any N M1) ratio of this study, which is only 4\%, is worth mentioning. In our opinion, the proportion of stage IV should be related to the definition of the subject being analyzed. For studies reporting high rates of stage IV ranging $35 \%-60 \%[8,10,11]$, patients who have undergone palliative surgery or who have been just diagnosed with biopsy or cytology had been included. In contrast, this rate was reported to be relatively low ranging 9\%-21\% in studies involving only patients with surgery $[9,12]$. The present study included only patients who underwent surgical treatment. It is rare to perform radical surgery for PNET with distant metastasis. Furthermore, the relatively high curative resection rate and exclusion of G3 are also the cause of the low stage IV ratio in the current study. This is consistent with report of a singlecenter study that patients with G3 accounts for a high percentage of all patients with ENETS stage IV. Of 53 patients with ENETS stage IV in the study, 27 patients (50.9\%) were G3 [26].

Several modalities of adjuvant treatment have been proposed that can be used to reduce tumor burden or inhibit cancer progression after recurrence of PNET [27]. In the case of chemotherapy, Ramirez et al. [28] demonstrated that combination treatment with capecitabine/ temozolomide has the benefit of prolonging the survival of patients with metastasis. Although all enteropancreatic neuroendocrine tumors were targeted, a randomized controlled study has suggested the effect of long-acting somatostatin analogues [29]. Unfortunately, just 67 of the 472 patients $(14.2 \%)$ enrolled in the current study were able to confirm whether they received adjuvant treatment. Of these 67 patients, seven had recurrence, and two of seven patients with recurrence received adjuvant treatment. Two of the patients treated with adjuvant treatment were all diagnosed with G2 and AJCC 8th stage II (T2NOM0), received adjuvant chemotherapy and survived to the last follow-up. The last follow-up point of each patient was 17 months and 4 months after the recurrence. Of the seven patients who had recurred, only one died, and he was one of the five who had not received any adjuvant treatment. He was a male patient with LVI, was diagnosed with G2 and AJCC 8th stage III (T3N1MO), and died 41 months after recurrence. Due to the small number of relapses that could be identified, it was not possible to verify statistically the prognostic factor influencing overall survival after recurrence or metastasis. Therefore, further studies using large samples that statistically demonstrate the role of adjuvant treatment for PNET is needed.

The present study has several limitations. First, we could not analyze the prognosis between functional tumor and nonfunctional tumor. Previous two studies have reported that functional neuroendocrine tumor is a prognostic factor for survival $[7,14]$. However, our multicenter database is missing a lot of information about these items. Thus, if this factor was included in the multivariate analysis process, more sophisticated and reliable statistical analysis would have been possible. Second, there is a potential for bias in the retrospective multicenter study design itself. In particular, this is relevant to the difference in the operative methods between various institutes. Considering the importance of lymph node metastasis to prognosis as previously mentioned in discussion, it is likely that the diversity of operative methods and lymphadenectomy have had some impact on survival.

In summary, this is the first large-scale validation of the AJCC 8th edition staging system for PNET. The revised 8th system provides better discrimination compared to that of the 7th edition system and ENETS staging system. Therefore, using the current system is expected to help stratify the patient's prognosis and provide clinical information.

\section{Conflicts of Interest}

Conflict of interest relevant to this article was not reported.

\section{Author Details}

${ }^{1}$ Department of Surgery, Konkuk University Choongju Hospital, Konkuk University School of Medicine, Chungju, ${ }^{2}$ Department of Surgery, Seoul National University College of Medicine, Seoul, ${ }^{3}$ Department of Surgery, Asan Medical Center, Ulsan University College of Medicine, Seoul, ${ }^{4}$ Department of Surgery, Seoul National University Bundang Hospital, Seongnam, ${ }^{5}$ Department of Surgery, Gangnam Severance Hospital, Yonsei University, Seoul, 'Department of Surgery, Chonnam National University Hwasun Hospital, Hwasun, ${ }^{7}$ Department of Surgery and Center for Liver Cancer, National Cancer Center, Goyang, ${ }^{8}$ Department of Surgery, Chonbuk National University Medical School and Hospital, Jeonju, ${ }^{9}$ Department of Surgery, Severance Hospital, Yonsei University College of Medicine, Seoul, ${ }^{10}$ Department of Hepatobiliary and Pancreas Surgery, Seoul St. Mary's Hospital, College of Medicine, The Catholic University of Korea, Seoul, ${ }^{11}$ Department of Surgery, Keimyung University Dongsan Medical Center, Daegu, ${ }^{12}$ Department of Surgery, Gyeongsang National University School of Medicine, Jinju, ${ }^{13}$ Department of Surgery, Ewha Womans University Mokdong Hospital, Ewha Womans University School of Medicine, Seoul, ${ }^{14}$ Department of Surgery, Chung-Ang University Hospital, Chung-Ang University, College of Medicine, Seoul, ${ }^{15}$ Department of Surgery, Dong- 
A University College of Medicine, Busan, ${ }^{16}$ Department of Surgery, Chonnam National University Hospital, Gwangju, ${ }^{17}$ Department of Surgery, Dongguk University Ilsan Hospital, Dongguk University
College of Medicine, Goyang, ${ }^{18}$ Department of Surgery, Samsung Medical Center, Sungkyunkwan University School of Medicine, Seoul, Korea

\section{References}

1. Amin MB, Edge S, Greene F, Byrd DR, Brookland RK, Washington $\mathrm{MK}$, et al. AJCC cancer staging manual. 8th ed. New York: Springer; 2017.

2. Yao JC, Eisner MP, Leary C, Dagohoy C, Phan A, Rashid A, et al. Population-based study of islet cell carcinoma. Ann Surg Oncol. 2007;14:3492-500.

3. Panzuto F, Boninsegna L, Fazio N, Campana D, Pia Brizzi M, Capurso G, et al. Metastatic and locally advanced pancreatic endocrine carcinomas: analysis of factors associated with disease progression. J Clin Oncol. 2011;29:2372-7.

4. Modlin IM, Moss SF, Chung DC, Jensen RT, Snyderwine E. Priorities for improving the management of gastroenteropancreatic neuroendocrine tumors. J Natl Cancer Inst. 2008;100: 1282-9.

5. Yao JC, Hassan M, Phan A, Dagohoy C, Leary C, Mares JE, et al. One hundred years after "carcinoid": epidemiology of and prognostic factors for neuroendocrine tumors in 35,825 cases in the United States. J Clin Oncol. 2008;26:3063-72.

6. Rindi G, Kloppel G, Alhman H, Caplin M, Couvelard A, de Herder WW, et al. TNM staging of foregut (neuro)endocrine tumors: a consensus proposal including a grading system. Virchows Arch. 2006;449:395-401.

7. Rindi G, Falconi M, Klersy C, Albarello L, Boninsegna L, Buchler MW, et al. TNM staging of neoplasms of the endocrine pancreas: results from a large international cohort study. J Natl Cancer Inst. 2012;104:764-77.

8. Fischer L, Kleeff J, Esposito I, Hinz U, Zimmermann A, Friess $\mathrm{H}$, et al. Clinical outcome and long-term survival in 118 consecutive patients with neuroendocrine tumours of the pancreas. Br J Surg. 2008;95:627-35.

9. La Rosa S, Klersy C, Uccella S, Dainese L, Albarello L, Sonzogni A, et al. Improved histologic and clinicopathologic criteria for prognostic evaluation of pancreatic endocrine tumors. Hum Pathol. 2009;40:30-40.

10. Ekeblad S, Skogseid B, Dunder K, Oberg K, Eriksson B. Prognostic factors and survival in 324 patients with pancreatic endocrine tumor treated at a single institution. Clin Cancer Res. 2008;14:7798-803.

11. Scarpa A, Mantovani W, Capelli P, Beghelli S, Boninsegna L, Bettini R, et al. Pancreatic endocrine tumors: improved TNM staging and histopathological grading permit a clinically efficient prognostic stratification of patients. Mod Pathol. 2010; 23:824-33.

12. Yang M, Zeng L, Zhang Y, Wang WG, Wang L, Ke NW, et al. TNM staging of pancreatic neuroendocrine tumors: an observational analysis and comparison by both AJCC and ENETS systems from 1 single institution. Medicine (Baltimore). 2015; 94:e660.

13. Bilimoria KY, Bentrem DJ, Merkow RP, Tomlinson JS, Stewart $\mathrm{AK}, \mathrm{Ko} \mathrm{CY}$, et al. Application of the pancreatic adenocarcinoma staging system to pancreatic neuroendocrine tumors. J Am Coll Surg. 2007;205:558-63.

14. Strosberg JR, Cheema A, Weber J, Han G, Coppola D, Kvols LK. Prognostic validity of a novel American Joint Committee on Cancer Staging Classification for pancreatic neuroendocrine tumors. J Clin Oncol. 2011;29:3044-9.

15. Strosberg JR, Cheema A, Weber JM, Ghayouri M, Han G, Hodul PJ, et al. Relapse-free survival in patients with nonmetastatic, surgically resected pancreatic neuroendocrine tumors: an analysis of the AJCC and ENETS staging classifications. Ann Surg. 2012;256:321-5.

16. Ellison TA, Wolfgang CL, Shi C, Cameron JL, Murakami P, Mun LJ, et al. A single institution's 26-year experience with nonfunctional pancreatic neuroendocrine tumors: a validation of current staging systems and a new prognostic nomogram. Ann Surg. 2014;259:204-12.

17. Rindi G. The ENETS guidelines: the new TNM classification system. Tumori. 2010;96:806-9.

18. Martin RC, Kooby DA, Weber SM, Merchant NB, Parikh AA, Cho CS, et al. Analysis of 6,747 pancreatic neuroendocrine tumors for a proposed staging system. J Gastrointest Surg. 2011;15:175-83.

19. Rindi G, Arnold R, Bosman FT. Nomenclature and classification of neuroendocrine neoplasms of the digestive system. In: Bosman FT, Carneiro F, Hruban RH, Theise ND, editors. WHO classification of tumours of the digestive system. 4th ed. Lyon: IARC; 2010. p. 13-4.

20. Edge SB, Byrd DR, Compton CC, Fritz AG, Greene FL, Trotti A. AJCC cancer staging manual. 7th ed. New York: Springer; 2010.

21. Luo G, Javed A, Strosberg JR, Jin K, Zhang Y, Liu C, et al. Modified staging classification for pancreatic neuroendocrine tumors on the basis of the American Joint Committee on Cancer and European Neuroendocrine Tumor Society systems. J Clin Oncol. 2017;35:274-80.

22. Hashim YM, Trinkaus KM, Linehan DC, Strasberg SS, Fields $\mathrm{RC}$, Cao D, et al. Regional lymphadenectomy is indicated in the surgical treatment of pancreatic neuroendocrine tumors (PNETs). Ann Surg. 2014;259:197-203.

23. Krampitz GW, Norton JA, Poultsides GA, Visser BC, Sun L, Jensen RT. Lymph nodes and survival in pancreatic neuroendocrine tumors. Arch Surg. 2012;147:820-7. 
24. Parekh JR, Wang SC, Bergsland EK, Venook AP, Warren RS, Kim GE, et al. Lymph node sampling rates and predictors of nodal metastasis in pancreatic neuroendocrine tumor resections: the UCSF experience with 149 patients. Pancreas. 2012; 41:840-4.

25. Nakakura EK. Challenges staging neuroendocrine tumors of the pancreas, jejunum and ileum, and appendix. Ann Surg Oncol. 2018;25:591-3.

26. Shiba S, Morizane C, Hiraoka N, Sasaki M, Koga F, Sakamoto $Y$, et al. Pancreatic neuroendocrine tumors: a single-center 20year experience with 100 patients. Pancreatology. 2016;16:99105.

27. Castellano D, Grande E, Valle J, Capdevila J, Reidy-Lagunes
D, O'Connor JM, et al. Expert consensus for the management of advanced or metastatic pancreatic neuroendocrine and carcinoid tumors. Cancer Chemother Pharmacol. 2015;75:1099114.

28. Ramirez RA, Beyer DT, Chauhan A, Boudreaux JP, Wang YZ, Woltering EA. The role of capecitabine/temozolomide in metastatic neuroendocrine tumors. Oncologist. 2016;21:671-5.

29. Rinke A, Muller HH, Schade-Brittinger C, Klose KJ, Barth P, Wied M, et al. Placebo-controlled, double-blind, prospective, randomized study on the effect of octreotide LAR in the control of tumor growth in patients with metastatic neuroendocrine midgut tumors: a report from the PROMID Study Group. J Clin Oncol. 2009;27:4656-63. 